\title{
The Internal Logic and Its Creativity of Leonard Bloomfield's Modern Linguistics
}

\author{
Yan Na \\ Xi'an Siyuan University \\ Literature School \\ Xi'an, China \\ e-mail: 362134959@qq.com
}

\begin{abstract}
Language is the inherent existence of human life in a world of meanings, which, through trace to its source, truth, goodness and beauty, not only helps people establish a kind of spiritual pursuit enriched with diversified life activities, but also embodies the national culture and folk information. As a famous American linguistician, Bloomfield epitomized the thoughts of modern linguistics into structuralism, collated all linguistic discussions and finally understood the basic characteristics and connotation of the essence of language ontology. Now, his thought of language philosophy still has important theoretical and practical significance in the contemporary.
\end{abstract}

Keywords-Bloomfield; Philosophy of Language; Logic; Meaning

\section{INTRODUCTION}

Language is closely related to human existence. Since ancient Greece, language has been regarded as a tool for social communication, and is often considered as an important basis for understanding the life in the universe. The basic components of different linguistic theories are all derived from the understanding of nature of language. In the late twentieth Century and early nineteenth Century, the field of philosophy was confronted with an unprecedented great crisis, which was widely suspected and attacked by the society. In the middle of the twentieth Century, the philosophy of language had ushered in a "Copernicus Revolution" with "human existence" as the basic starting point. The center of the study had been conversed from epistemology to the language and the language had no longer been the tool to express imperfect ideas in the traditional philosophy, but a truth-speaking system in the pursuit of universal validity, which had become a starting point and foundation for the philosophy to reflect on its own traditions. Since the twentieth Century, language has changed from a communication tool to the way of human existence, thus forming the third linguistic turn in the philosophy. The "linguistic turn" is the basic component that cannot be avoided in the process of social progress, which makes the language become the core of philosophy research. This turn in depth has been involved in the whole symbolic systems and ideographic systems in depth and in breadth has showed the change of the understanding of the nature of philosophy, which decides the overall development trend of philosophy into the modernization[1]. The approach to quest in the language philosophy has turned into people's subjective initiative and subjectiveness of cognition, which proves that the starting point and the foothold of contemporary philosophy all contain the themes of human nature and tend to the harmonious construction between people and the world.

As a famous American linguistician, Bloomfield had collated all linguistic discussions and scientifically summarized the theories and principles of historical linguistics, and he has played a bridge role in the history of development of linguistics. In Language, he was getting rid of all the contents of introspective psychology in linguistics and has developed a school of his own study of linguistics as a separate science, which inspired people's great enthusiasm to follow his linguistic ideas. Language philosophy is man's theory of self-consciousness. It expresses man's exploration of the value, meaning and nature of human life and the questioning of the supreme unity in the world and guides the construction of human life and the world. Language is a net of the symbols made with historical experience of human activities to construct the world. There is a real crisis in the language modernization. Bloomfield's philosophy of language inspires us to reflect on life and rationally grasp the society. This, in the context of China's undergoing modernization, is undoubtedly of great theoretical and practical significance.

\section{DEVELOPMENT LOGIC OF BLOOMFIELD'S PHILOSOPHY OF LANGUAGE}

Different understandings of the essence of language define people's overall grasp of the orientation of language existence and a series of subjective issues, such as the world, the mind, the meaning, the truth, and so on. Since ancient Greece, man began to ponder the language in different degrees. Until Aristotle's time, the question of language was formally put on the agenda of philosophy. In ancient Greece, language was thought to be "a tool, an object serving human", and it was considered that our thoughts were governed by the way language was expressed. The "tool " theory has been extended to the modern society and with the formation and development of modern logic, man's subject status get hitherto unknown vigor and vitality, "man" has become the subject in the contemporary philosophy of language in accordance with the philosophy of subjectivity[2]. In this context, questioning the true state of language becomes the main content of research on modern philosophy. The "imprisoned" theory of the language as a tool is broken and people's understanding of the nature of language has undergone dramatic changes. 
At that time, known as the father of modern linguistics, Saussure had published a book called "Course in General Linguistics", in which his incisive and sharp linguistic thoughts attracted a large number of scholars and also affected the formation of the whole linguistic schools. Bloomfield is the second major representative after Saussure in descriptive linguistics. His magnum opus Language has a high status and great influence in the whole structural linguistics circles[3]. The structural linguistics, derived from Saussure's linguistic theories, is characterized by its opposition to isolated analysis of linguistic phenomena and its proposition of the systematic study of it. This is mainly influenced by Saussure's thought on language. Saussure believed that language is a complete symbol system composed of many elements of language which reveals the network structure hierarchy according to its inherent regularity. In the description of different levels of linguistic structures, we should strictly pay attention to the spoken language and attach great importance to record the actual language and the importance of synchronic description, so as to show the basic characteristics - behaviorism and pure description of language structure. We must admit that Bloomfield inherited some of Saussure's ideas, but he and Saussure had certain differences in the definition of language analysis methods, which can be told from the language theory of Bloomfield in different periods in the direction. On the whole, Bloomfield's philosophy of language has experienced two periods, namely, the early mentalistic linguistics and semantics and late behavioristic linguistics and semantics.

There is a significant transcendentalism in Bloomfield's early thought that he clearly points out that the essence of language is not in the communication or the logic of communication and that the philosophers replace their universality with their own linguistic structures, ignoring the differences in thinking that in fact exist. Therefore, we cannot use the language universals and logic to "standardize" the human language activities and this language semantic concept has laid a solid foundation for its late theory of language. In Bloomfield's view, the basic composition of language is a variety of human experience types accompanied by habitual collections, in which each type of experience is unique, and the main source of experience is the user's associative habits[4]. As thinking animals, only if man analyzes the empirical components through the brain can any form of meaning be understood and these independent components in essence are all the matter of psychological aspects. To Bloomfield, this kind of mentalistic linguistics seems to be more scientific and rational. He believes that only if we explain the language and semantics based on psychology can we avoid the logic and introspective subjective interpretation to the linguistic phenomenon in previous linguistics. On the contrary, it will be difficult for us to get down to the linguistic phenomenon itself, or we can only use "imagination" instead of the true state of things. Bloomfield argues that language behavior is observable and can be empirical, and that the meaning of language must be explained by the individual's customary behavior, which is greatly subjective, so understanding the language from the synchronic level is the most appropriate. In fact, it is the process of the alternative response that people make when they are substantially stimulated. It is true that the language of the synchronic system is a complex symbolic system, which can describe the subjective structure or form. We can link the various experiences in our life with our corresponding statements or words so that we can summarize the laws of human thinking activities and provide good conditions for us to decompose the elements of various generalized experiences and the grammatical categories that constitute them.

Weiss's behaviorism did have an impact on Bloomfield's view of language. Bloomfield's thought in the middle and later periods rejects the concept of "mind", "consciousness" and "meaningless" in the early days. He argues that the meaning of linguistic form is not a kind of material object that is deduced from logical thinking and the occurrence of the language meaning is the whole linguistic context reacted with external stimulus, which has a great resemblance to mechanicalism, so the later thoughts of Bloomfield turned to the behavioristic language semantics[5]. In his view, the former language researchers use abstract names to analyze grammar, with philosophical forms and logical standards to elaborate on grammar, but in fact it is the speaker that gives meaning to specific words, which is the reaction due to the language stimulation. Therefore, he believes that all empirical studies do belong to the scope of linguistic sciences, or even it cannot be said to exist. The mentalistic meaning on the form of language is the response that the role of the subjects makes when they are in the expression or acceptance of the form of language. This is the speculation made based on the actual situation, a psychological speculative interpretation that is divorced from the actual scene of the language and a popular term only limited to the internal body, so this falseness undoubtedly exacerbated the ambiguity and uncertainty of the language. In Bloomfield's view, language does not exist in the real world of our life, and we can only try to use stimulus-response theory to explain the process of language generation and understanding through the presence of language and try to avoid the study of its meaning. The process of language activity generation is multifaceted and complex, which crosses several areas of physics, physiology and psychology. In simple terms, the "language form" is nothing more than a specific response to the stimulus source in the "specific context" of the individual's action on the receptor. The environment and the response to the environment are the meaning of this form of language. In Bloomfield's view, the language phenomenon is a link in the physiological chain "stimulus (external physics) - response (physiological behavior)" .It can be seen that the understanding of linguistic meaning is based on a fixed and conventional social meaning, which extends man from the physical universe into the symbolic universe, and builds a polymer basis for the mutual understanding and communication between people. 


\section{MEANING AND FORM OF BLOOMFIELD'S PHILOSOPHY OF LANGUAGE}

The perfect combination of American behavioral psychology theory and American structural linguistics theory provides a systematic and scientific theoretical basis for the existence of linguistic signs beyond physical existence. The core theory of linguistic philosophy is the theory of meaning, so the linguistic philosophers propose different theories of meaning. Bloomfield argues that language is a formal structure that includes a central system (divided into three sub-systems of grammar, phoneme, and morpheme) and a peripheral system (divided into semantic and phonetic systems).Language reveals the relationship between man and being, and man is also the existence among language that depends on the acquisition of direct experience. Man gets the understanding of the world in the understanding to language, that is to say, the language created the possibility for human beings to have the world and man masters the existence of the world through the language world. Due to the influence of Saussure's language split and his "language is form rather than entity", Bloomfield divides linguistic research into two parts: "semantics" and "phonology". Semantic description usually includes grammar and vocabulary (i.e. language form). He advocates that the study of language shall start from the language form. Meaning is a very complex, multilevel and difficult-to-face problem in Language. This concept is based on the speaker-speech-listener's response. On the question of "meaning", he thinks that all kinds of objective and observable forms of language exist in the real world must be scientifically and precisely understood, and then the meaning can be understood. At the time, we lacked the deep understanding of the knowledge world and do not have the "scientific and accurate knowledge", so it is difficult to make the right judgments to the meaning of language form, thereby increasing the language complexity and agnosticism. This is why there have been inconsistent and different explanations when people interpret Bloomfield, which seems to fall into a contradictory situation. Bloomfield argues that the meaning of linguistic form is "in a particular context in which a speaker initiates a language-type stimulus to stimulate the listener to respond to the objective environment" and he distinguishes the behaviors in the context into linguistic act and non-linguistic act. Bloomfield's analysis of "meaning" mixes the form of language, and human's limitations restrict human's understanding of the meaning of language form which shows the ambiguity of meaning. Besides, the core of meaning is the person who speaks. The connotation of the words is flexible, so the integration of specific situations is the key to the study of language.

Bloomfield's "meaning" is inseparable from the form and the form is used to express the meaning. "The form of language is simple in structure and it is only a combination of dozens of phonemes. Only by fully understanding the speaker's situational meaning, we can correctly identify the distinguishing features of language stimulation", he says. It requires us to use the real environment of the language to clarify the semantics. Only those closest to the formal characteristics in the meaning system can be called its basic meaning. Bloomfield points out that language is a transcendent reality that exists in the minds of everyone and the factors that actors make concrete behaviors are complex and involve people's life experiences, living habits, mental states and various nonphysical factors, so the relationship between form and meaning is arbitrary. The context has a certain role in restricting the form of language. The form of language cannot be separated from its meaning. The reason why people can speak is that he subordinate to speech and listen to the speech, so meaning can only be attached to some formal features. Therefore, Bloomfield defines the grammatical rules of language as "meaningful configurations of various forms". All human social behaviors are the results of repeated external stimuli. Scenes for a language form to occur can be ever-changing, which means that each language form has a constant and specific meaning. Form is used to express the meaning and to understand the situation is the basis for scientific grasp of semantics. Therefore, Bloomfield advocates that the analysis of language shall begin with smaller language units. He observes language phenomena from the perspective of mechanical theory, and accordingly puts forward the famous transfer formula: $\mathrm{S}$ (stimulus source) $\rightarrow \mathrm{r}$ (alternative reaction) $\ldots \mathrm{S}$ (alternative stimulus) $\rightarrow \mathrm{R}$ (actual reaction).It can be seen that the language is actually a series of stimulating and reactive behaviors, which achieves the external actual response through the external language stimulus. The grammatical arrangement is composed of many grammatical units. The semantic change is the change of the lexical meaning in the grammatical function without the change of the form. The grammar unit is the smallest unit in the form of grammar. The individual grammar unit is considered as a common grammar arrangement. Man is a rational animal and the language comes from the natural generation of rationality. There is no rationality without language. However, what makes people really become the human is the spiritual strength, which is the simplicity of the human nature.

Bloomfield accepted Saussure's argument that language was a symbolic system and he had perfected the thought on the system. Language for the first time objectively and scientifically describes the language, developed a set of strict methods and procedures for language description and analysis to make the language description method in the objectivity and formalization reach an unprecedented height. In addition, it also restricts the scope of language development. On the one hand, observability is plain and cannot go deep into the essence of things, and its internal order of development is extremely complex. It is not feasible to make deduction and reasoning without thinking and logic; on the other hand, Bloomfield makes the language study limited to collecting materials and classifying it. In reality, human morpheme continues to be produced and changed with the environment. The collection of morphemes is tantamount to a drop in the ocean. In fact, the interpretation of semantics lacks scientificity, which ultimately can only lead to meaningless accumulation. Of course, the phoneme analysis and grammatical analysis use a set of tight terms and methods, which is of pioneering significance for the 
extension of linguistics. In Language, Bloomfield emphasizes the complexity of the meaning. Meaning is a constructive phenomenon that can be directly interpreted and analyzed by semantic priming, which reflects the common cognitive characteristics of mankind and is a study not to exclude but to emphasize the psychological significance. He emphasizes that the language study must take the language form as the starting point from a standpoint of unknown meaning, excluding the psychological systems of Wundt and others, which set a model for later linguistic research. As we all know, language distinguishes man from animal. Language becomes the basic way of communication and expression of thought and becomes the symbolic existence of man. In fact, language and man are the same. Any practice that excludes meaning must not withstand the test of time.

\section{BLOOMFIELD'S PHILOSOPHY OF LANGUAGE ON INNOVATION TO "MODERNITY"}

As the spirit, the "Modernity", like the material, is the objective existence in modern society, and is fundamentally a way of discourse. Language for the first time has made an objective and scientific description on the formal system of language, which had laid a solid foundation for the collection of material, proposal of assumptions, revision of assumptions and construction of theory or rules. Bloomfield's language thoughts promote the construction of modern philosophy and pragmatics, emphasize the experiential and humanistic nature of language and provide effective evidence for the problems caused by the main trend - "cultural shift" in current fields, which shows the importance of reflections on "Yes" and "True" in language studies. Bloomfield broke the Saussure's binary-opposition thought on his structural linguistics, basically got out of the impact of positivism, digest the metaphysics of presence and deepen and expand the study on the essential nature of meaning in contemporary language, which provides a new theoretical paradigm for us to explore the meaning of language, language form, form structure and other mysteries.

In addition, Bloomfield inspires us to have dialogues with linguists about their authority on creation and recreation of language in the knowledge study, and make deeply excavation and exploration in the digestion and integration of the great scholars' theories and insights of the time. He emphasizes the importance of practice and calls for an analytical introspection to our own language experience. There is no doubt that language is not only the biological attribute of human beings, but also is the humanized language. The starting point of language research is not the so-called "language" as a complex cultural object, but as a communicative behavior. That is, the language is formed by human experience and cognition, so the language study must be based on the principle of human nature - "reality, cognition and language". The meaning of any language can only be attached to some formal features, but the environmental factors and material factors where man lives are changing and the elements for generation of the meaning of language are also constantly changing, so it requires us to combine the form and meaning and return to the essence of grammar, which fully reflects the humanistic spirit in postmodern philosophy.

Bloomfield thinks the language is endowed with sociality. Language is the link between the inside and the outside world, and is the tool that people use to express thoughts, feelings, emotions, wills and behaviors. The diversity of language connotation is a manifestation of the different patterns of human existence. People are connected by language to others, society and the world. In practice, language not only plays a role of "messenger", it also bears a command, proposes a discourse and forms a kind of hegemony and so on. The diversity of language is a huge treasure house that contains rich knowledge of mankind, and it is also a manifestation of the collection of national cultural information and associative relations. Since modern times, because of the query on "metaphysical" question and the admiration on "science of science", the language becomes a strict network of rationality. The orderly world can be seen through the surface of the network, but another scene will be found when going deeply inside the world. On the one hand, philosophy has cast a "scientific" appearance, but in fact, the language has become an island; on the other hand, it is far from the ultimate concern and supremacy of mankind, which leads to the loss of modern humanistic spirit and the crisis of human survival due to development of science and technology, highlighting the manifestation of being devoid of human ultimate concern.

The ultimate concern is not only the important content of all philosophy, but also the essence and core of philosophical theory. With the acceleration of the globalization process of knowledge, when the boundaries of language are gradually expanding, some languages face the extinction and imminent danger of language. The non-dominant language and culture is gradually "murdered" and "swallowed", which makes people get lost in the messy language game. The human consciousness of language expression is the part of human consciousness that needs externalization and that can be externalized by the language form. The meaning can lead to people's social behavior and can be materialized into concrete social system, which will promote the establishment of social order or social development. It is precisely because of the importance of language activities to mankind that the modern logic can provide a powerful weapon for philosophers to re-understand the nature of language. It is true that the ultimate concern of any philosophy is essentially man himself, and when we get satisfaction in our material life, our spiritual world is gone into emptiness. However, the ultimate concern of language philosophy not only carries the bottom line, conscience and sense of responsibility in the life practice of human beings, but also undertakes reflections on the normality, soul and dignity of human nature, life, human spirit.

\section{ACKNOWLEDGMENT}

Fund Project: This paper is a research result of the phased research of education science planning project in shaanxi province in 2016. Project Number: SGH16H263 


\section{REFERENCES}

[1] Liu Zhaolin. Language or Human - Essence and Significance of Dispute between Rousseau and Herder's Thoughts on Language Origin. Foreign Languages Research, (1), pp.98-102, 2013.

[2] Ye Qichang. "People Have Language"and "'People among Lanuage" Heidegger on Herder. Foreign Languages Research,(2),pp.27-31, 2008.

[3] Si Fuzhen.Head Theory and "Bloomfield Puzzle"- Reply to Zhou Guoguang. Contemporary Linguistics, (1), pp.60-70, 2006.

[4] Huang Qian.Comment on Bloomfield's Thoughts on Form and Meaning in Language.Study in Language and Linguistics, (S1), pp.293-296,2002.

[5] Wen Fanglian.Bloomfield's Semantic Thought and Its Interpretation. Journal of Shaanxi Normal University (Philosophy and Social Sciences Edition), (S2), pp.165-167, 2004. 